\title{
Modeling Botswana Beef-Cattle Price Dynamics
}

\author{
Paul Kundai Ziwakaya, Edward M. Lungu \\ Department of Mathematics and Statistical Sciences, Botswana International University of Science and Technology, Private Bag 16 \\ Palapye, Botswana \\ Email: paul.ziwakaya@studentmail.biust.ac.bw, lungue@biust.ac.bw
}

How to cite this paper: Ziwakaya, P.K. and Lungu, E.M. (2021) Modeling Botswana Beef-Cattle Price Dynamics. Journal of Mathematical Finance, 11, 84-106. https://doi.org/10.4236/jmf.2021.111004

Received: December 8, 2020

Accepted: February 21, 2021

Published: February 24, 2021

Copyright $\odot 2021$ by author(s) and Scientific Research Publishing Inc. This work is licensed under the Creative Commons Attribution International License (CC BY 4.0).

http://creativecommons.org/licenses/by/4.0/ (c) (i) Open Access

\begin{abstract}
We investigate the dynamics of the beef-cattle pricing which is affected by several factors such as beef supply, demand for foreign currency, etc. The model incorporates mean-reversion to give insights into the relationship between supply to a developed region (or country) and a third world country's demand for hard currency. We consider the beef-cattle industry which is segmented into two markets: the Farmer-Local Cattle Agency (LCA) market in which the LCA buys cattle from the farmers and the LCA-European Union (EU) market in which the LCA exports beef to the EU. Using the Botswana-EU as an example, we investigate the performance of the Botswana Meat Commission (BMC) which buys cattle from the farmers and exports beef to the EU based on the price acceptable to the EU and ask whether the agreed price between the $\mathrm{BMC}$ and the $\mathrm{EU}$ can ever translate into fair price between the farmer and the BMC. Our study has concluded that the operational problems faced by the BMC are an indication that the BMC is passing on the bulk of what it receives from the EU to the farmers. We have made suggestions on how the BMC can reduce its operational risks.
\end{abstract}

\section{Keywords}

Stochastic Mean, Mean-Reversion, Geometric Mean Reversion, Beef-Cattle

\section{Introduction}

The Botswana-European Union (EU) beef-cattle trade is an outstanding example of cooperation between a Western block and a third world country (Botswana). Although this trade showed promise, it has of late exhibited cracks as the EU has forged more trade agreements with other beef exporters such as South America, Australia, New Zealand, etc. An example of this occurred when the EU stopped all meat imports from Botswana and demanded a thorough cleanup of the abattoirs [1]. The beef-cattle industry is of strategic importance to Botswana as a 
major source of foreign currency. At the time the EU took this decision, the beef export industry was Botswana's second biggest earner of foreign currency behind diamonds. In recent years, tourism has overtaken the beef export industry as the quantity of beef exported has declined. To understand the performance of the beef industry, numerous models incorporating spot prices, demand, quality, supply and seasonality as well as convenience yield behavior in the industry have been developed [2] [3] [4]. Piot-Lepetit [2] examined the price evolution of porcine and bovine for the EU and its Member States (MS) and concluded that a higher dispersion of prices at the MS level did not yield an acceptable price process between the two parties. Several other studies have made contributions, and have arrived at similar conclusions citing the unpredictability of the dynamics of the industry as one of the reasons. Although the intuitive approaches have met with numerous shortcomings, such as, inability to account for stochasticity in variables, these approaches have nevertheless permitted one to reach useful preliminary conclusions.

The export market in Botswana is dominated by a government parastatal organisation called Botswana Meat Commission (BMC). BMC has experienced substantial changes in prices over the past with major surges during the past three decades [4] [5] [6] [7]. The beef-cattle prices dramatically changed from $B W P 4.56$ in 1992 to nearly $B W P 32.20$ in recent years (although the weak exchange rate plays a significant role), see Table A1 in Appendix A1 for an overview. Between the period of 1992 to 2018, the price upswing decelerated resulting in decreased beef-cattle prices. Jeffiris [5] analyzed the changes in prices for the Botswana beef-cattle industry and found out that changes in the EU have significant impacts on the cattle prices in Botswana. Botswana meat exports to the EU increased from 13,245 tonnes in 1968 to 29,368 tonnes in 2017 [8]. During the period 1968 to 1990 's, Botswana enjoyed unlimited preferential market access to the EU. This has changed as the country now competes with countries such as Brazil, Australia, Argentina, China and the United States of America (USA) [4].

This competition for the EU market has introduced uncertainty in the beef prices. Tothova [9] investigated price volatility in order to determine whether volatility had increased after some time at the EU and global levels. She compared price volatility in relation to other economic variables such as stocks, spot prices, volume of trade and so on. The results showed that events from the past have an impact on the present price variability. The question in the case of Botswana is what historical events have significant effects on the Botswana-EU beef-cattle trade.

Important contributions have been made by Schwartz [10] who analyzed three stochastic models of commodity prices that considered mean reversion. The first model was a one-factor model in which the logarithm of the spot price of the commodity followed a mean reverting process. The second model considered convenience yield as a second stochastic factor of the commodity, which followed a mean reverting process. The third model incorporated stochastic inter- 
est rates. The investigation uncovered solid mean reversion in the commodity prices. Schwartz and Smith [11] formulated a two-factor model of commodity prices that permitted variability in the mean level and mean-reversion in short-term prices. They modeled spot prices as a Brownian motion process that can be decomposed into short-term and a long-term component according to their individual dynamics. By separating short-term and long-term price features and utilizing futures prices to differentiate between them, Schwartz and Smith [11] provided a conceptual model for developing richer models of commodity price movements.

In this paper we incorporate the aspect of mean reversion and a time dependent stochastic mean reverting process for the price. Unlike stock prices which generally exhibit upward trends in the long run as investors benefit from the long term dividend yields and earnings, beef prices, show a level dependent behavior over a long period since supply and demand dictate the prices. However, one of the fundamental distinguishing characteristics exhibited by beef prices is mean-reverting behavior (for example, Schwartz [10], Casassus and CollinDufresne [12], Bessembinder et al. [13], Pyndick [14], and Routledge et al. [15] etc., for empirical proof supporting the utilization of mean-reversion for commodity prices). We have used a Geometric Mean Reversion process (GMR) to model the pricing process for Botswana beef-cattle farming. This approach was pioneered by Dixit and Pindyck [16] in an economic context.

The paper is organized as follows, in Section 2, we present model formulation, section and a preliminary result of the study using a Bivariate analysis for Farmer-BMC price $S_{1}(t)$ and BMC-EU prices $S_{2}(t)$, Section 3, we present the model that we formulated following the influences that affect the pricing process in the Botswana beef-cattle industry. Most of the influences were not explicitly considered, but we assumed they fall under the volatility part. In Section 4, we provide a lemma on the positivity of our model, the proof was built on Lyapunov type function and four cases were considered for our model. Model approximation and calibration are given in Appendix A3, in Section 5 we discuss the findings from our study and perform sensitivity analysis. Subsequently, we concluded in Section 6 and gave some remarks in the Appendix.

\section{Model Formulation}

In our model we assume that the information available to the BMC is the average price of beef $\bar{S}(t)$, whose future trend is not known. In general, Equation (1) below represents the evolution of price $S(t)$ at time $t$ based on the EU price.

$$
S(t)=\bar{S}(t)+a_{i}, i=1,2,
$$

where, $\bar{S}_{i}(t)$ is the mean price and $a_{i}$ is a random variable.

\subsection{Preliminary Analysis}

Prior to our stochastic model we present some preliminary results associated 
with the price data sets. As noted before that the Botswana beef-cattle industry is divided into two markets segments described earlier.

Let $S_{1}(t)$ denote the Farmer-BMC price and $S_{2}(t)$ the BMC-EU price. Figure 1 shows time plot for annual averaged beef-cattle prices for Farmer-BMC and BMC-EU from the year 1992 to 2018.

Note that while the ratio of the price of Farmer-BMC to BMC-EU was 0.65 in 1992 this ratio declined to 0.30 in 2015. This could be a result of competition in the beef market where the seller had to accept a lower price to secure the export quarter. The mean and standard deviation for each of the two price processes are given in Table 1 (see Table A1 in Appendix A1 for an overview of data that was used).

We conclude that the random variable $a_{i}, i=1,2$ is purely a white noise process. The Pearson's correlation coefficient for the two price processes is given by,

$$
r=\frac{\frac{\sum_{i=1}^{n}\left(S_{1}(t)-\bar{S}_{1}\right)\left(S_{2, i}-\bar{S}_{2}\right)}{n-1}}{\sqrt{\sum_{i=1}^{n}\left(S_{1}(t)-\bar{S}_{1}\right)^{2} \sum_{i=1}^{n}\left(S_{2, i}-\bar{S}_{2}\right)^{2}}}=0.8999 .
$$

Table 1. Mean and standard deviation for $S_{1}(t), S_{2}(t)$ and their respective residuals.

\begin{tabular}{ccccc}
\hline & $S_{1}(t)$ & $a_{1}$ & $S_{2}(t)$ & $a_{2}$ \\
\hline Mean & 12.4133 & 0.0033 & 23.3407 & 0 \\
Standard deviation & 10.2059 & 10.2059 & 13.9738 & 13.9738 \\
\hline
\end{tabular}

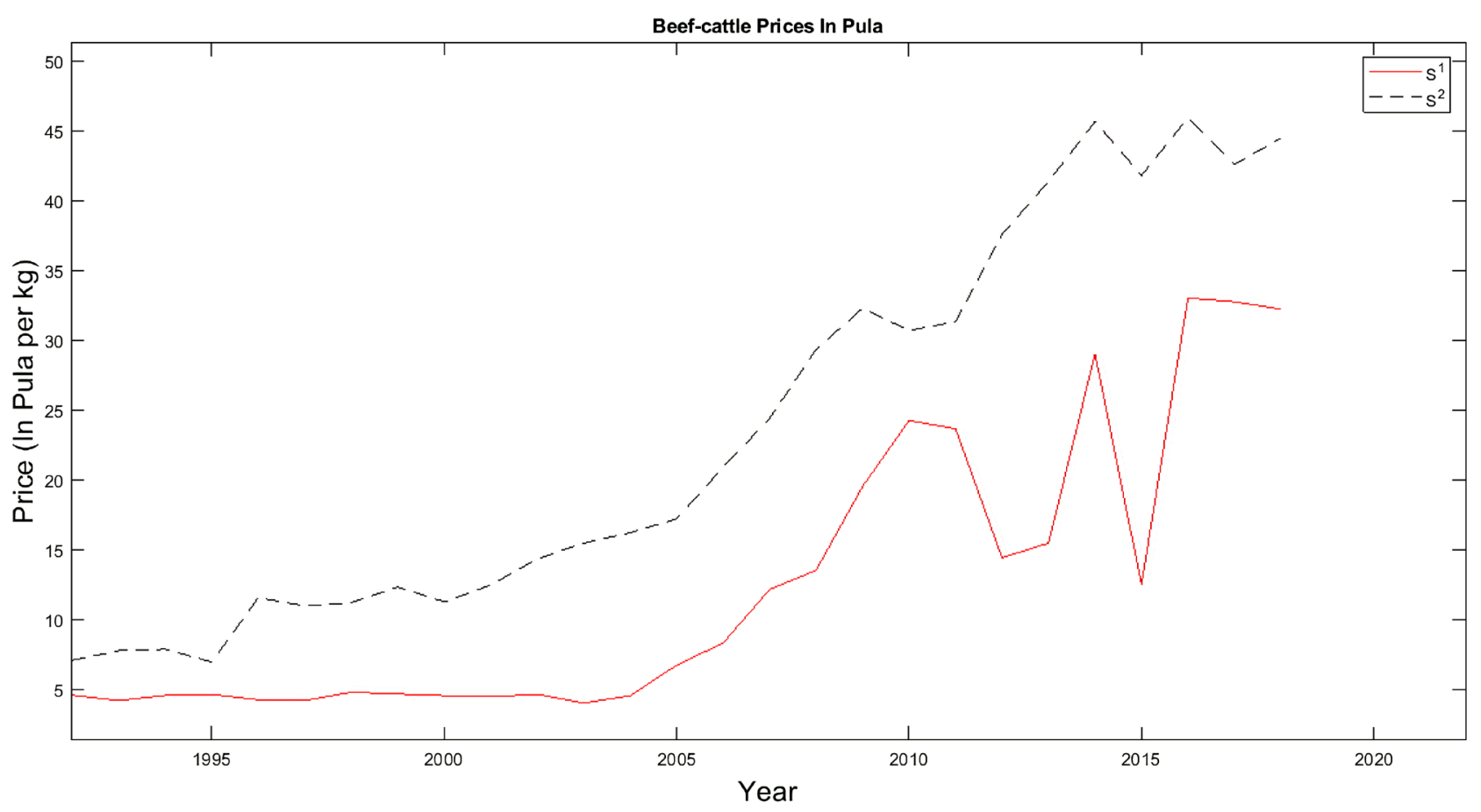

Figure 1. Time plot for Farmer-BMC prices and BMC-EU prices for the years 1992 to 2018. 
This confirms a strong positive correlation between the Farmer-BMC price $S_{1}(t)$ and BMC-EU price $S_{2}(t)$ suggested by Figure 1. Based on the values $a_{i}, i=1,2$ and the value of the correlation coefficient in Equation (2) one can interpret that BMC passes on to farmers the gain or loss it incurs from trading with the EU.

The relationship between $S_{1}(t)$ and $S_{2}(t)$ is of interest. We assume a relationship between $S_{1}(t)$ and $S_{2}(t)$ of the type:

$$
S_{2}(t)=\omega(B) S_{1, t-b} \text {. }
$$

where, $B$ is the backward shift operator and $b$ is the delay parameter. Our task is to find the transfer function $\omega(B)$ and $b$ which for this relationship holds.

In the next subsection we discuss the concept of linear prices translation in the Botswana beef-cattle industry using the Box and Jenkins procedure [17].

\subsection{Price Translation in the Botswana Beef-Cattle Industry}

Suppose there exists $N$ price observations $S_{i}, i=1,2$, where they are collected at equispaced intervals on the time horizon $[0, T]$ (yearly averages in this case) and pairwise observations as $\left(S_{1,1}, S_{2,1}\right),\left(S_{1,2}, S_{2,2}\right), \cdots,\left(S_{1, N}, S_{2, N}\right)$ and finite realization of a discrete bivariate process with the $S_{1}(t)$ as the independent variable and $S_{2}(t)$ as the dependent variable (see Table A4 in Appendix A4 for the notations used throughout this paper). We need to find the weights $\left\{w_{k}\right\}$ (response functions), where $k=0,1, \cdots$ of the pricing process

$$
S_{2, t}=w(B) S_{1, t-b} \text {. }
$$

where $w(B)=v_{0}-v_{1} B-v_{2} B^{2}-\cdots$ is called the transfer function. Let, $s_{1, t}=\nabla^{d} s_{1, t}$ and $s_{2, t}=\nabla^{d} s_{2, t}$ be incremental changes for the Farmer-BMC prices and BMC-EU prices, respectively. The constant $d$ denotes the degree of differencing, $\nabla=(1-B)$, then for any series $\left\{M_{t}\right\}, M_{t-b}=B^{b} M_{t}$, we can show on differencing Equation (4) that $S_{2, t}$ and $s_{1, t}$ satisfy the same transfer function model as do $S_{2, t}$ and $S_{1, t}$ i.e.

$$
s_{2, t}=w(B) s_{1, t-b} .
$$

Writing Equation (5) (the linear filter) in a parsimonious way as in Box and Jenkins [18] we have,

$$
\delta(B) s_{2, t}=\rho(B) s_{1, t-b} \text {. }
$$

where

$$
\begin{gathered}
\delta(B)=1-\delta_{1} B-\delta_{2} B^{2}-\cdots-\delta_{r} B^{r} \\
\rho(B)=\rho_{0}-\rho_{1} B-\rho_{2} B^{2}-\cdots-\rho_{h} B^{h} .
\end{gathered}
$$

We compared Equations (5) and (6) to obtain:

$$
\begin{gathered}
w(B)=\delta^{-1}(B) \rho(B) \\
w_{j}=0, j<b \\
w_{j}=\delta_{1} w_{j-1}+\delta_{2} w_{j-2}+\cdots+\delta_{r} w_{j-r}-w_{0}, j=0,1, \cdots, b
\end{gathered}
$$




$$
\begin{gathered}
w_{j}=\delta_{1} w_{j-1}+\delta_{2} w_{j-2}+\cdots+\delta_{r} w_{j-r}-\rho_{j-b}, j=(b+1), \cdots,(b+h) \\
w_{j}=\delta_{1} w_{j-1}+\delta_{2} w_{j-2}+\cdots+\delta_{r} w_{j-r}, j>(b+h) .
\end{gathered}
$$

Theoretically, a plot of the weights $w_{k}, k=0,1, \cdots$ against lag $k$ provides a pictorial representation of the impulse response function. In reality, however (considering the beef-cattle industry of Botswana in particular) the system involves noise or disturbances whose net effect influences the predicted model by an amount $\eta_{t}$, so that the combined translation function-noise model may be written as;

$$
s_{2, t}-\delta^{-1}(B) \rho(B) s_{1, t-b}=\eta_{t} .
$$

where $s_{2, t}$ and $s_{1, t}$ are stationary time series for $d$ differencing. Using the Box and Jenkins [17] pre-whitening procedure we can fit an ARIMA model to the differenced input series $S_{1, t}$ as our initial procedure as;

$$
\phi(B) s_{1, t}=\theta(B) \alpha_{t},
$$

where the variable $\alpha_{t}$ represents a pure white noise process, $\left.\phi(B)=1-\sum_{i=1}^{p}{ }_{1}\right\rangle \phi_{i} B^{i}$ and $\theta(B)=1-\sum_{j=1}^{p}{ }^{\gamma} \theta_{j} B^{j}$ are moving average and autoregressive polynomials respectively. Note that from Equation (15) the transformation $\theta(B) \theta^{-1}(B)$ transforms the correlated series of the dependent variable $s_{1, t}$ to the uncorrelated pure random process $\alpha_{t}$ such that,

$$
\alpha_{t}=\theta^{-1}(B) \phi(B) s_{1, t} .
$$

Transforming, to the BMC-EU prices (output series), we obtain

$$
\beta_{t}=\phi(B) \theta^{-1}(B) s_{2, t} .
$$

Calculating, the cross-covariance function of the filtered input and output ( $\alpha_{t}$ and $\beta_{t}$ and multiplying both sides of Equation (15) by $\phi(B) \theta^{-1}(B)$ gives:

$$
\beta_{t}=w(B) \alpha_{t}+\varepsilon_{t} \text {. }
$$

where, $\varepsilon_{t}=\phi(B) \theta^{-1} n_{t}$ is the transformed noise series. Multiplying both sides of Equation (18) by $\alpha_{t-k}$ and taking expectation, noting that $\alpha_{t}$ and $n_{t}$ are uncorrelated yields:

$$
w_{t}=\frac{\mathbb{E}\left[\alpha_{1-b}, \beta_{t}\right] \sigma_{\beta}}{\sigma_{\alpha}} .
$$

where $\sigma_{\beta}^{2}$ and $\sigma_{\alpha}^{2}$ are the variances of $\alpha_{t}$ and $\beta_{t}$ respectively, and $\mathbb{E}\left[\alpha_{1-b}, \beta_{t}\right]$ is the cross-covariance function at lag $k$. The estimate of the impulse response function $\left(w_{k}\right)$ determined as outlined above are found to be reliable [17] and we used them as a basis for estimating constants $r, h$ and $b$. Furthermore, considering the orders of parameters $r$ and $h$ of $\delta(B)$ and $\rho(B)$ of Equation (12), we seek to identify Bivariate Autoregressive Integrated Moving Average (BARIMA) models that describe the noise at the BMC-EU prices $S_{2}(t)$ (the output).

If we consider $b=0, \delta^{-1}(B)=1, \rho(B)=\rho=1$, Equation (14) is transformed into 


$$
S_{1}(t)-S_{2}(t)=\eta_{t}
$$

In Figure 2 is a scatter plot of BMC-EU prices against Farmer-BMC prices.

A scatter plot of $S_{1}(t)$ against $S_{2}(t)$ (Figure 2) justifies the subsequent section for which a dynamic model for the beef-cattle industry for Botswana is presented.

\section{Dynamics of the Price: Stochastic Model}

The bivariate relationship between the Farmer-BMC and BMC-EU prices in 2.2 has shown that the difference between the two prices is a white noise process (Figure 2). In this section, we propose to formulate the Farmer-BMC price as an Ornsten-Uhlenbeck type process with the BMC-EU price as the stochastic mean to which the Farmer-BMC price reverts. Let $S(t)=\left(S_{1}(t), S_{2}(t)\right)$ be a price process, where $S_{1}(t)$ represent the Farmer-BMC price and $S_{2}(t)$ represents the BMC-EU price. Denote by, $B_{1}(t)$ and $B_{2}(t)$ the noise for the Farmer-BMC and the BMC-EU prices, respectively. The price process $S(t)$ is assumed to mimic a GMR as in Ewald and Yang [19].

For simplicity of notation, we define the state variables $\left(x_{1}, x_{2}\right)=\left(S_{1}(t), S_{2}(t)\right)$ where $x_{2}$ is assumed to be the mean of the price process $x_{1}(t)$. The GMR model can be written as:

$$
\begin{gathered}
\mathrm{d} x_{1}=\kappa\left(x_{2}-x_{1}\right) x_{1} \mathrm{~d} t+\sigma_{1} x_{1} \mathrm{~d} B_{1} \\
\mathrm{~d} x_{2}=\sigma_{2} x_{2} \mathrm{~d} B_{2} .
\end{gathered}
$$

where, $\sigma_{1}>0, \sigma_{2}>0$ and $\mathrm{d} B_{1} \mathrm{~d} B_{2}=\rho \mathrm{d} t$ and $\kappa$ is the level dependent mean reverting speed. Note that we assume the mean to be purely stochastic, since the BMC has no knowledge about the price it will be offered by the EU. We can write the system (21)-(22) in matrix form as

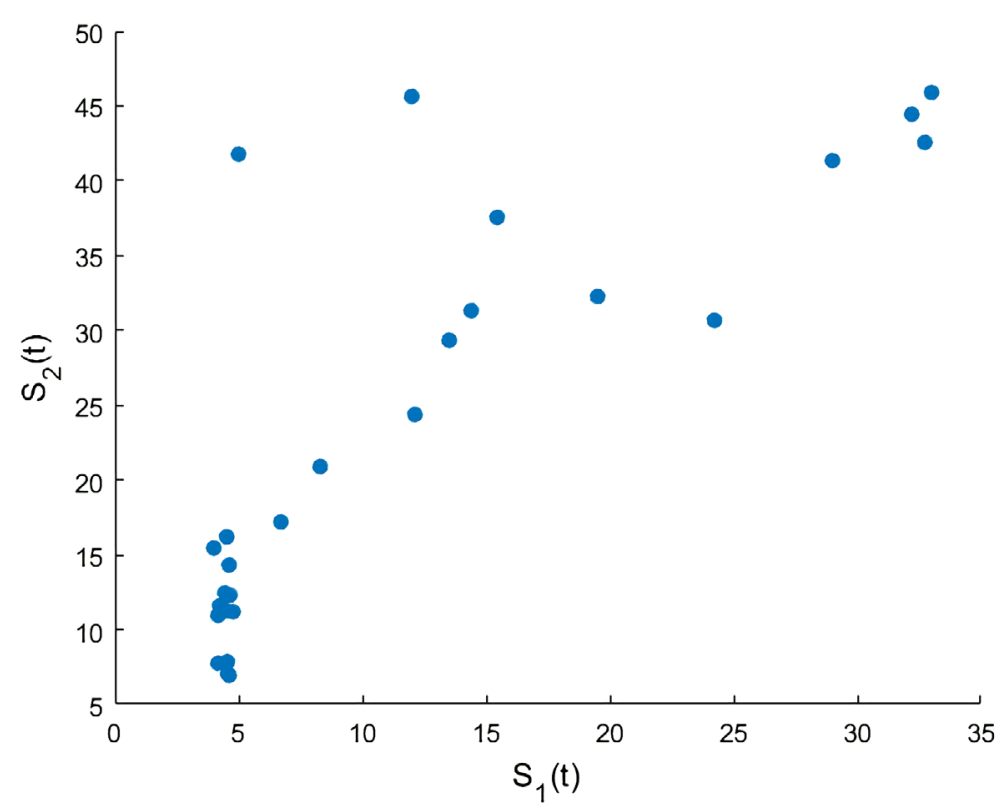

Figure 2. Scatter plot of BMC-EU prices against Farmer-BMC prices. 


$$
\mathrm{d} x_{t}=f\left(x_{t}\right) \mathrm{d} t+\sigma\left(x_{t}\right) \mathrm{d} B,
$$

where $x_{t}=\left(x_{1}(t), x_{2}(t)\right)^{\mathrm{T}}$

$$
f\left(x_{t}\right)=\left(\begin{array}{c}
\kappa\left(x_{2}-x_{1}\right) x_{1} \\
0
\end{array}\right) ; \sigma\left(x_{t}\right)=\left(\begin{array}{cc}
\sigma_{1} x_{1} & 0 \\
0 & \sigma_{2} x_{2}
\end{array}\right) ; \mathrm{d} B=\left(\begin{array}{l}
\mathrm{d} B_{1} \\
\mathrm{~d} B_{2}
\end{array}\right) .
$$

The solution of (23) is not unique due to nonlinear terms $x_{1} x_{2}$ and $x_{1}^{2}$ in the drift of the Equation (21). We want to define conditions on $f\left(x_{t}\right)$ for the system (23) to have a unique solution.

Remark. The solution of the stochastic model (23) does not tend to any nearby steady state (see for example Asfaw et al. [20]). The stability analysis in this study refers to quasi stability about a deterministic steady state $\bar{X}$ so that instead of considering individual paths of $x_{t}-\bar{x}$, we shall evaluate the expectation of $\left|x_{t}-\bar{x}\right|^{2}$.

Let $\Omega=\left\{\left(x_{1}, x_{2}\right) \in \mathbb{R}_{+}^{2}, x_{i} \geq 0, i=1,2\right\}$ be a positive region under study and consider the system (23) with initial values $x^{0}=\left(x_{1}^{0}, x_{2}^{0}\right) \in \mathbb{R}_{+}^{2}$. It is easy to show that (23) can be modified (see, Gard [21] for details) such that the nonlinear terms $x_{1} x_{2}$ and $x_{1}^{2}$ are replaced by linearly bounded terms $g_{t}\left(x_{1}\right) g_{t}\left(x_{2}\right)$, where

$$
g_{\epsilon}(s)= \begin{cases}0 & \text { if } s<0 \\ s & \text { if } 0 \leq s \leq \frac{1}{\epsilon} \\ \frac{1}{\epsilon} & \text { if } s>\frac{1}{\epsilon}\end{cases}
$$

and $\epsilon$ is an arbitrary small number. We denote the modified $f\left(x_{t}\right)$ in (23) by $f^{\epsilon}\left(x_{t}^{\epsilon}\right)$ and consider the following stochastic system

$$
\mathrm{d} x_{t}^{\epsilon}=f^{\epsilon}\left(x_{t}^{\epsilon}\right) \mathrm{d} t+\sigma\left(x_{t}^{\epsilon}\right) \mathrm{d} B .
$$

Clearly (see Øksendal $6^{\text {th }}$ edition [22]),

$$
\begin{gathered}
\left|f^{\epsilon}(x)-f^{\epsilon}(\bar{x})\right| \leq K_{\epsilon}|x-\bar{x}| \\
|\sigma(x)-\sigma(\bar{x})| \leq K|x-\bar{x}|
\end{gathered}
$$

For all $x, \bar{x} \in \mathbb{R}^{2}$ where $K_{\epsilon}$ and $K$ are constants.

Denote by $\tau_{\epsilon}$ the next exit time of $x_{t}^{\epsilon}$ from the domain

$$
\mathbb{R}^{2} \cap\left\{\max _{1 \leq i \leq 2} x_{i}<\frac{1}{\epsilon}\right\},
$$

If this domain contains the initial point $x^{0}$ then the system (21)-(22) possesses a nonnegative solution for $t>0$ in this domain.

\section{Lemma 1 (Positivity Region)}

For any finite $T>0$ the solution $x_{t}^{\epsilon}$ of the system (24) with initial condition $x^{0} \in \mathbb{R}_{t}^{2}$ remains in $\mathbb{R}_{t}^{2}$ for all $t<T \wedge \tau_{\epsilon}$ (where $T \wedge \tau_{\epsilon}$ denotes the smaller between $T$ and $\tau_{\epsilon}$ ) so that the components $x_{t}^{\epsilon}$ satisfy $x_{i, t}>0$, if $t \wedge T, \tau_{\epsilon}$ for $i=1,2$. Furthermore, $\mathbb{P}\left(\tau_{\epsilon}<T\right)<C_{o} \tau_{\epsilon}$, where $C_{0}$ is a constant independent 
of $x^{0}$.

\section{Proof}

We want to prove first that a non-negative solution does not exit the positive domain $\Omega$. We introduce a Lyapunov type function

$$
\begin{aligned}
& V=x_{1}-\kappa_{1} \ln x_{1}+x_{2}-\kappa_{2} \ln x_{2} \\
& \mathrm{~d} V=\left(1-\frac{\kappa_{1}}{x_{1}}\right) \mathrm{d} x_{1}+\left(1-\frac{\kappa_{2}}{x_{2}}\right) \mathrm{d} x_{2}+\frac{1}{2} \frac{\kappa_{1}}{x_{1}^{2}}\left(\mathrm{~d} x_{1}\right)^{2}+\frac{1}{2} \frac{\kappa_{2}}{x_{2}^{2}}\left(\mathrm{~d} x_{2}\right)^{2} \\
&=\left(1-\frac{\kappa_{1}}{x_{1}}\right)\left[\kappa\left(x_{1}-x_{2}\right) x_{1} \mathrm{~d} t+\sigma_{1} x_{1} \mathrm{~d} B_{1}\right] \\
&+\left(1-\frac{\kappa_{2}}{x_{2}}\right) \sigma_{2} x_{2} \mathrm{~d} B_{2}+\frac{1}{2} \kappa_{1} \sigma_{1}^{2} \mathrm{~d} t+\frac{1}{2} \kappa_{2} \sigma_{2}^{2} \mathrm{~d} t \\
&= {\left[\kappa x_{1} x_{2}-\kappa_{1} x_{1}^{2}-\kappa_{1} \kappa x_{2}+\kappa_{1} \kappa x_{1}+\frac{1}{2} \kappa_{1} \sigma_{1}^{2}+\frac{1}{2} \kappa_{2} \sigma_{2}^{2}\right] \mathrm{d} t } \\
&-\kappa_{1} \sigma_{1} \mathrm{~d} B_{1}-\kappa_{2} \sigma_{2} \mathrm{~d} B_{2}+\sigma_{1} x_{1} \mathrm{~d} B_{1}+\sigma_{2} x_{2} \mathrm{~d} B_{2} \\
& \leq {\left[\kappa x_{1} x_{2}+\kappa_{1} \kappa x_{1}+\frac{1}{2} \kappa_{1} \sigma_{1}^{2}+\frac{1}{2} \kappa_{2} \sigma_{2}^{2}\right] \mathrm{d} t+\sigma_{1} x_{1} \mathrm{~d} B_{1}+\sigma_{2} x_{2} \mathrm{~d} B_{2} } \\
&= \mathcal{M}(t) \mathrm{d} t+\sum_{i=1}^{2} \sigma_{i} x_{i} \mathrm{~d} B_{i} .
\end{aligned}
$$

where

$$
\mathcal{M}(t)=\kappa x_{1} x_{2}+\kappa_{1} \kappa x_{1}+\frac{1}{2} \kappa_{1} \sigma_{1}^{2}+\frac{1}{2} \kappa_{2} \sigma_{2}^{2} .
$$

Integrating (26), we obtain

$$
\int_{0}^{T \wedge \tau_{\epsilon}} \mathrm{d} V \leq \int_{0}^{T \wedge \tau_{\epsilon}} \mathcal{M} \mathrm{d} s+\sum_{i=1}^{2} \int_{0}^{T \wedge \tau_{\epsilon}} \sigma_{i} x_{i} \mathrm{~d} B_{i} .
$$

Taking expectation we obtain

$$
\mathbb{E}\left[V\left(T \wedge \tau_{\epsilon}\right)\right] \leq \mathbb{E}\left[V\left(x^{0}\right)\right]+\mathcal{M}\left(T \wedge \tau_{\epsilon}\right) .
$$

Note that if the path $x_{t}^{\epsilon}$ is such that it exits $\mathbb{R}_{t}^{2}$ at $T \wedge \tau_{\epsilon}$ then by definition of (25) the function $V$ becomes $\infty$ at the exit point. In view of (26) the probability of that happening is zero. This completes the proof.

\section{Special Cases}

We consider the following four cases of the system (21)-(22):

\section{Lemma 2}

For the case $\sigma_{1}=\sigma_{2}=0$, the system (21)-(22) possesses two equilibrium points one of which is stable and the other unstable.

\section{Proof}

Take $\sigma_{1}=\sigma_{2}=0$, the system (21)-(22) becomes

$$
\begin{gathered}
\frac{\mathrm{d} x_{1}}{\mathrm{~d} t}=\kappa\left(x_{2}-x_{1}\right) x_{1} \\
\mathrm{~d} x_{2}=0, x_{2}=m, m \text { is a constant. }
\end{gathered}
$$

Equation (30) has two equilibrium points $(0, m)$ and $(m, m)$ The transient 
solution of Equation (30) for $x_{1}(t)$, for $x_{2}(t)=m$, is given by

$$
x_{1}=\frac{m}{1+\mathrm{e}^{-\kappa m t}} .
$$

Clearly, as $t \rightarrow \infty, x_{1} \rightarrow m$ implying that the movement is away from the unstable equilibrium point $(0, m)$ towards the stable equilibrium point $(m, m)$.

Remark: When there is no volatility the price $x_{1}(t)$ would remain constant about the mean price $m$ which economically is not a good situation for either the Farmer-BMC price or the BMC-EU price as neither the farmer nor BMC would generate sufficient capital to expand.

\section{Lemma 3}

For the case $\sigma_{1}=0, \sigma_{2} \neq 0$, the system (21)-(22) possesses one stable equilibrium point $(0,0)$.

Proof

For $\sigma_{1}=0, \sigma_{2} \neq 0$, the system (21)-(22) becomes,

$$
\begin{gathered}
\mathrm{d} x_{1}=\kappa\left(x_{2}-x_{1}\right) x_{1} \mathrm{~d} t \\
\mathrm{~d} x_{2}=\sigma_{2} x_{2} \mathrm{~d} B_{2} .
\end{gathered}
$$

Equation (33) yields the solution

$$
\begin{gathered}
x_{2}=\exp \left[-\frac{1}{2} \sigma_{2}^{2} t+\sigma_{2} B_{2}\right] \\
\mathbb{E}\left[x_{2}\right]=\exp \left[-\frac{1}{2} \sigma_{2}^{2} t\right] \rightarrow 0 \text { as } t \rightarrow \infty .
\end{gathered}
$$

Solving for $x_{1}$ in terms of $x_{2}$, we obtain

$$
x_{1}=\frac{x_{2} \exp \left[\kappa x_{2} t\right]}{1+\exp \left[\kappa x_{2} t\right]}=\frac{\exp \left[-\frac{1}{2} \sigma_{2}^{2} t+\sigma_{2} B_{2}\right] \exp \left[\kappa \exp \left[-\frac{1}{2} \sigma_{2}^{2} t+\sigma_{2} B_{2}\right] t\right]}{1+\exp \left[\kappa \exp \left[-\frac{1}{2} \sigma_{2}^{2} t+\sigma_{2} B_{2}\right] t\right]}
$$

As $t \rightarrow \infty, \quad x_{2} \rightarrow 0, \quad x_{1} \rightarrow 0$.

Remark: For $\sigma_{1}=0, \sigma_{2} \neq 0$ the system (21)-(22) possesses one stable equilibrium point $(0,0)$ which implies the collapse of business. This solution is unrealistic but it cautions against decisions such as price control without taking into account supply and demand. This is the case in the African beef-cattle market where fixing prices is usually a political decision.

\section{Lemma 4}

For $\sigma_{1} \neq 0, \sigma_{2}=0$ the system (21)-(22) is reducible to an Ornstein-Uhlenbeck type process, which yields Ornstein-Uhlenbeck gains or losses.

\section{Proof}

Note that for $\sigma_{1} \neq 0, \sigma_{2}=0$ the system (21)-(22) becomes,

$$
\mathrm{d} x_{1}=\kappa\left(m-x_{1}\right) x_{1} \mathrm{~d} t+\sigma_{1} x_{1} \mathrm{~d} B_{1},
$$

which can be written in the form, 


$$
\mathrm{d} x_{1}=f\left(x_{1}\right) \mathrm{d} t+g\left(x_{1}\right) \mathrm{d} B_{1}
$$

where,

$$
f\left(x_{1}\right)=\kappa\left(m-x_{1}\right) x_{1} \text { and } g\left(x_{1}\right)=\sigma_{1} \text {. }
$$

Defining,

$$
A(x)=\frac{f(x)}{g(x)}-\frac{1}{2} g^{\prime}(x),
$$

then based on Gard (1988, chapter 4) [21], Equation (37) can be reduced to a standard Ornstein-Uhlenbeck process if,

$$
\left(\frac{\left(g A^{\prime}\right)^{\prime}}{A^{\prime}}\right)=0 .
$$

From (39), it is easy to show that

$$
\begin{aligned}
\left(\frac{\left(g A^{\prime}\right)^{\prime}}{A^{\prime}}\right) & =\left(\frac{g^{\prime} A^{\prime}+g A^{\prime \prime}}{A^{\prime}}\right)=\left(\frac{g^{\prime} A^{\prime}}{A^{\prime}}\right)=\frac{A^{\prime}\left(g^{\prime} A^{\prime}\right)^{\prime}-\left(g^{\prime} A^{\prime}\right) A^{\prime \prime}}{\left(A^{\prime}\right)^{2}} \\
& =\frac{A^{\prime}\left(g^{\prime} A^{\prime \prime}+A^{\prime} g^{\prime \prime}\right)-\left(g^{\prime} A^{\prime}\right) A^{\prime \prime}}{\left(A^{\prime}\right)^{2}}=0 .
\end{aligned}
$$

Following Gard (1988, chapter 4) [21], the solution of (37) is given by,

$$
x_{1}=\frac{\exp \left\{\left(m-\frac{1}{2} \sigma_{1}^{2}\right) t+\sigma_{1}^{2} B_{1, t}\right\}}{x_{1,0}^{-1}+m \int_{0}^{t} \exp \left\{\left(\kappa m-\frac{1}{2} \sigma_{1}^{2}\right) s+\sigma_{1} B_{1, s}\right\} d s} .
$$

If we rewrite (37) as,

$$
\frac{\mathrm{d} x_{1}}{x_{1}}=\kappa\left(m-x_{1}\right) \mathrm{d} t+\sigma_{1} \mathrm{~d} B_{1},
$$

then, we can see that the left hand side of (44) represents the gains or losses, while the right hand side represents an Ornstein-Uhkenbeck process. We shall compute the solution (43) and the Ornstein-Uhlenbeck gains or losses (44) numerically.

\section{Proposition 1}

For $\sigma_{1} \neq 0, \sigma_{2} \neq 0$, the system (21)-(22) yields Ornstein-Uhlenbeck gains or losses that revert to a fluctuating mean, $m$.

Remark: The system (21)-(22) can be written as,

$$
\begin{gathered}
\frac{\mathrm{d} x_{1}}{x_{1}}=\kappa\left(x_{2}-x_{1}\right) \mathrm{d} t+\sigma_{1} \mathrm{~d} B_{1} \\
\mathrm{~d} x_{2}=\sigma_{2} x_{2} \mathrm{~d} B_{2} .
\end{gathered}
$$

\section{Proof}

The approach used in lemma (4) can be used to prove proposition (1) and the system (45)-(46) has the following solution, 


$$
\begin{gathered}
x_{1}=\frac{\exp \left\{\left(x_{2}-\frac{1}{2} \sigma_{1}^{2}\right) t+\sigma_{1}^{2} B_{1, t}\right\}}{x_{1,0}^{-1}+x_{2} \int_{0}^{t} \exp \left\{\left(\kappa x_{2}-\frac{1}{2} \sigma_{1}^{2}\right) s+\sigma_{1} B_{1, s}\right\} d s} \\
x_{2}=\exp \left[-\frac{1}{2} \sigma_{2}^{2} t+\sigma_{2} B_{2}\right] .
\end{gathered}
$$

Clearly, the relative gains or losses in price (right hand side of (45) is of Ornstein-Uhlenbeck type and are level dependent (mean reverting to $x_{2}$ given in (34). We present the solution for $\sigma_{1} \neq 0$ and $\sigma_{2} \neq 0$ in section (5) numerically.

\section{Results}

In this section, we present the results of the special cases in Section 4.1. We explore the impact of changes in the level of noise (changes in $\sigma_{1}$ and $\sigma_{2}$ ) on, among other things, the stability of the steady states and its implications. Figure 2, shows the Botswana beef-cattle prices for the case $\sigma_{1}=0, \sigma_{2}=0$. The price $x_{1}$ increases gradually to the mean level $x_{2}$, and stays at that level in agreement with lemma 2.

Figure $3(\mathrm{~b})$, shows the result for $\sigma_{1}=0, \sigma_{2} \neq 0$. The price, $x_{1}$, increases to a fluctuating mean level $x_{2}$. The equilibrium point is not a constant unlike the situation in Figure 3(a), because the noise degrades the stability (this is quasi-stable). Note that this case represents a scenario when the volatility is very low. Figure 3(c) and Figure 3(d) show that for as long as $\sigma_{1}$ remains zero, increasing the volatility $\sigma_{2}$ increases the magnitude of the fluctuations in both $x_{1}$ and $x_{2}$, but the two prices remain close to one another. Quasi stability of $x_{1}$ and $x_{2}$ is still maintained.

Figure 4 shows a scenario when the volatility of the price $x_{1}$ is varied and the volatility of $x_{2}$ remains zero. Figure 4(a) shows that the price $x_{1}$ increases and fluctuates about the constant price $x_{2}$. The fluctuations are very small for

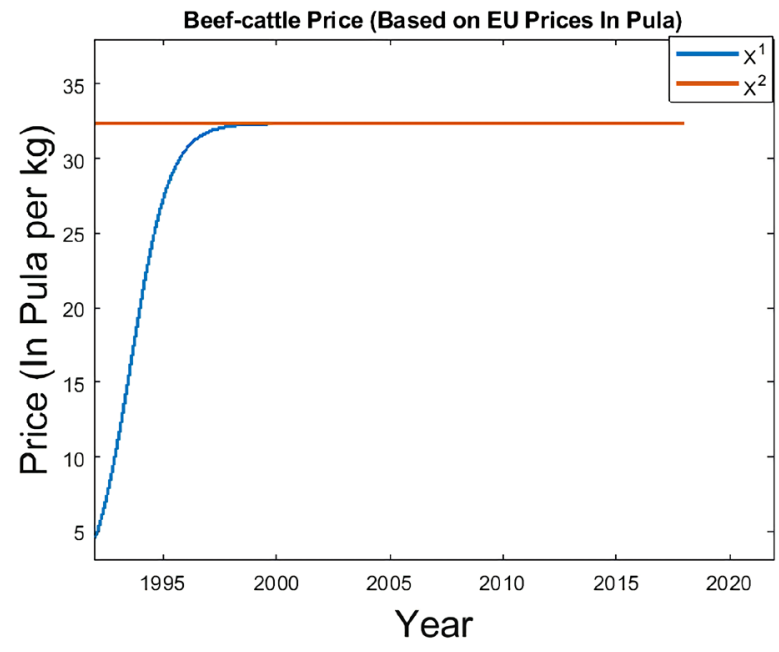

(a)

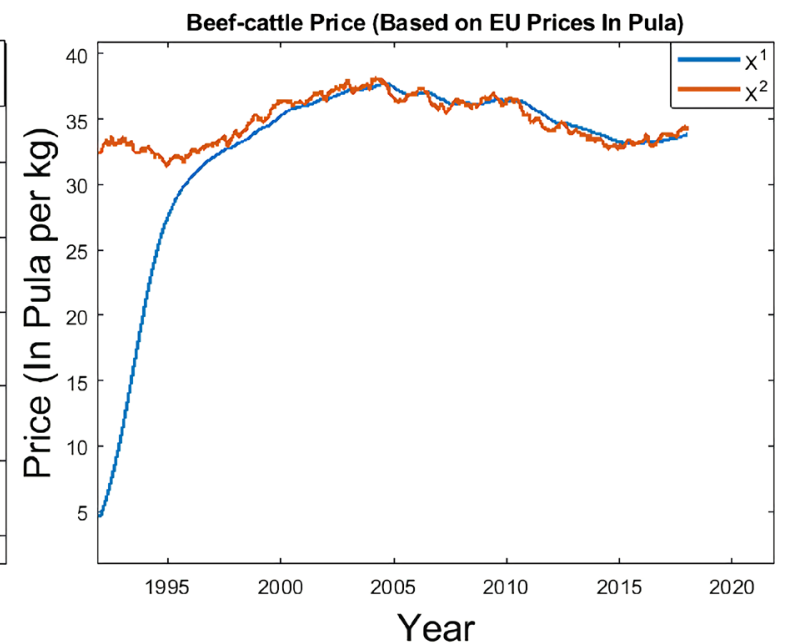

(b) 


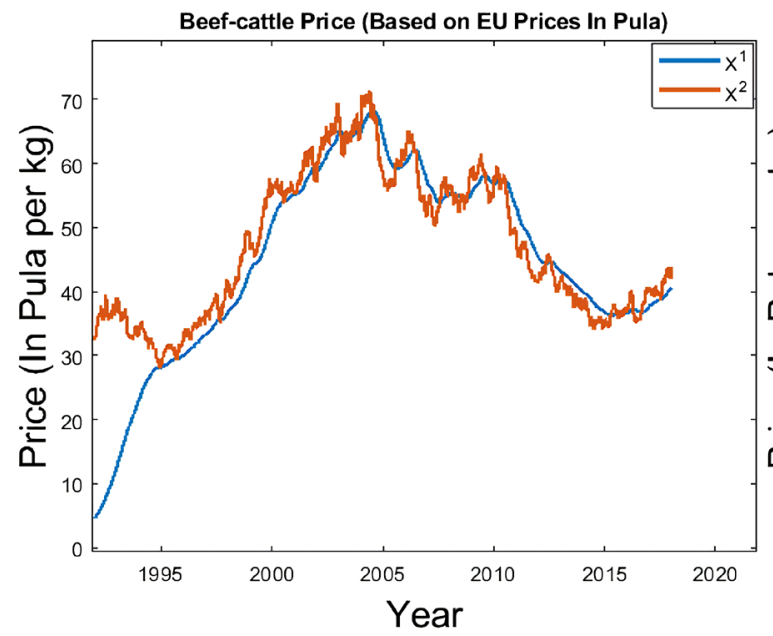

(c)

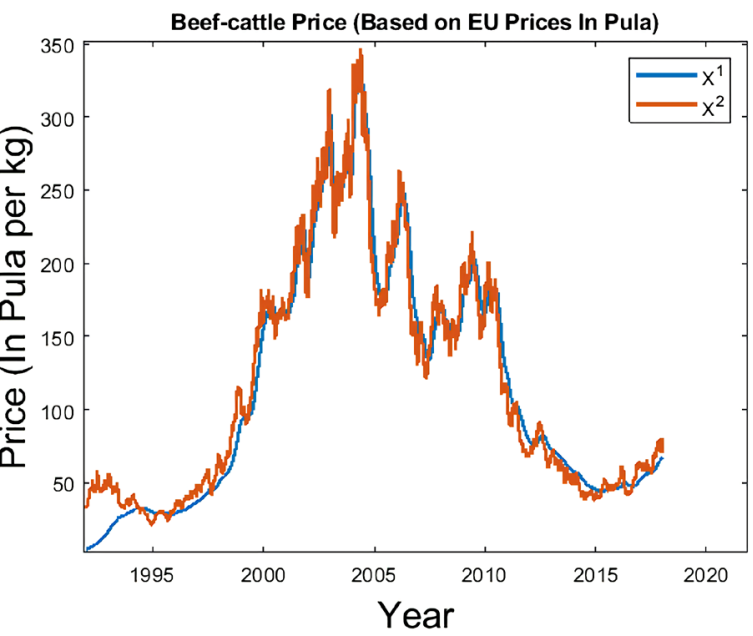

(d)

Figure 3. Botswana beef-cattle prices following a deterministic GMR. (a) $\sigma_{1}=0, \sigma_{2}=0$ (b) $\sigma_{1}=0, \sigma_{2}=0.021$ (c) $\sigma_{1}=0, \sigma_{2}=0.1$ (d) $\sigma_{1}=0, \sigma_{2}=0.3$.

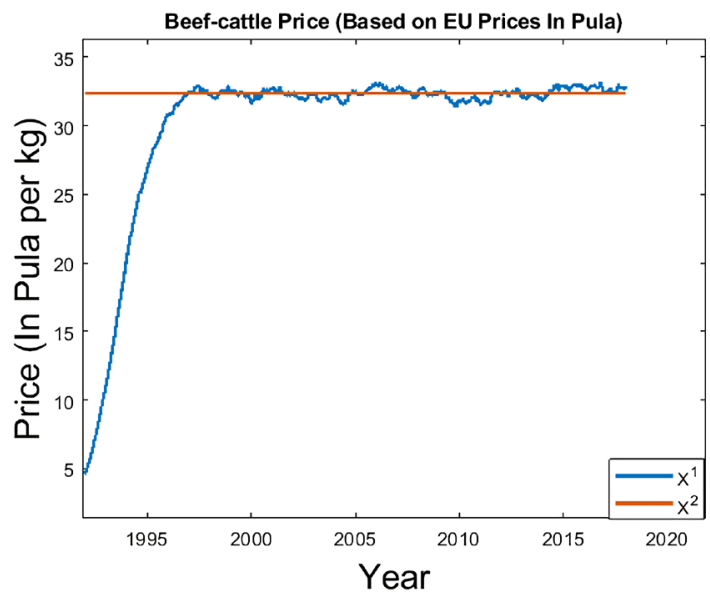

(a)

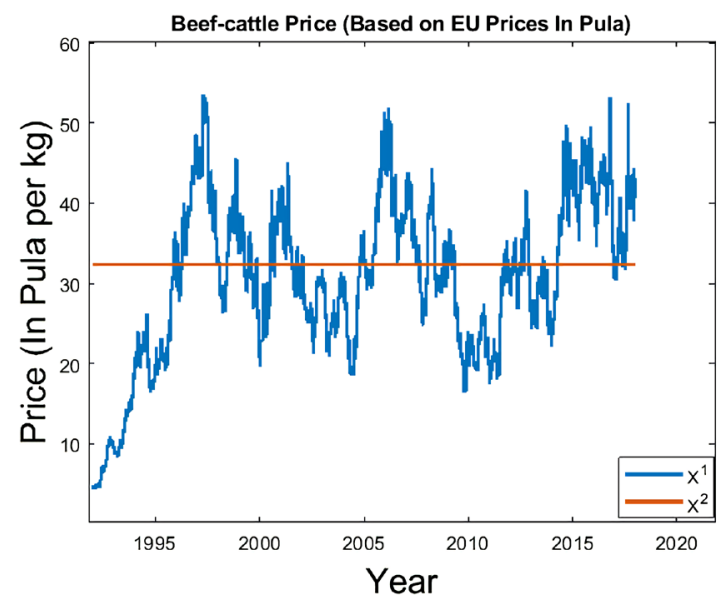

(c)

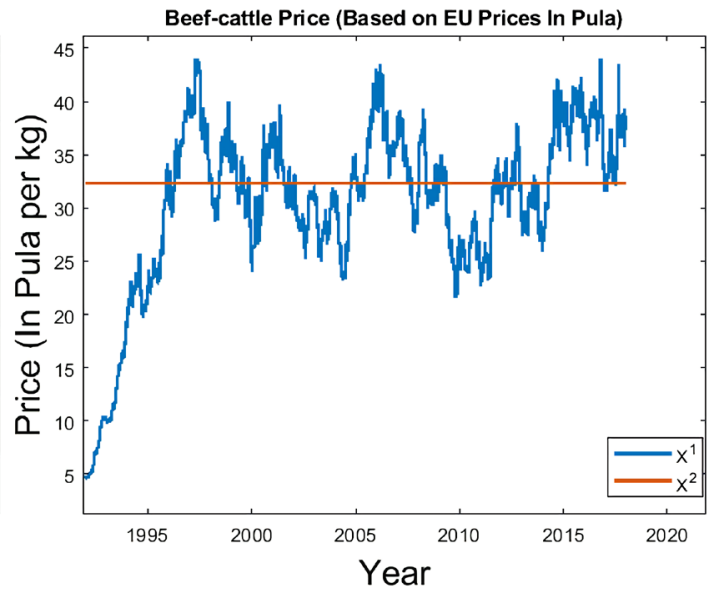

(b)

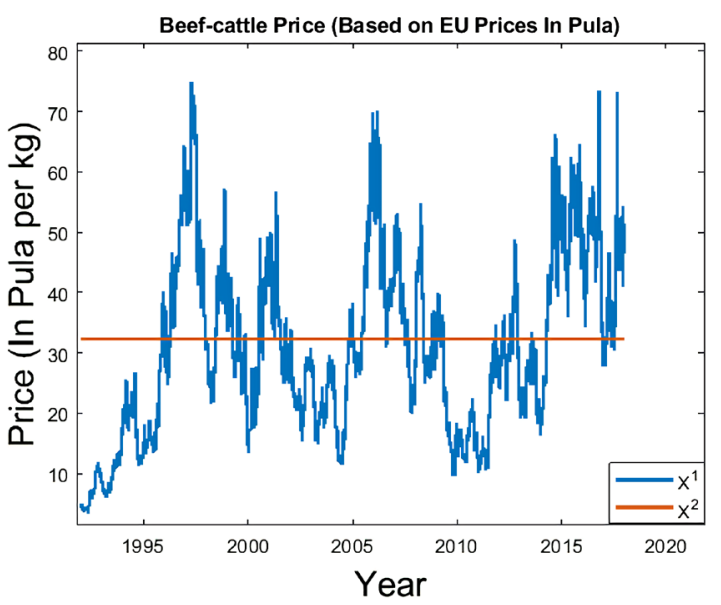

(d)

Figure 4. Botswana beef-cattle prices following Stochastic GMR and mean-reversion level. (a) $\sigma_{1}=0.019$, $\sigma_{2}=0 .(\mathrm{b}) \sigma_{1}=0.124, \sigma_{2}=0 \quad$ (c) $\sigma_{1}=0.4, \sigma_{2}=0$ (d) $\sigma_{1}=0.7, \sigma_{2}=0$. 
small values of $\sigma_{1}$. This represents a stable equilibrium point which is degraded by the noise.

As we increase the volatility $\sigma_{1}$ the fluctuations about a constant mean increase significantly as depicted in Figures 4(b)-(d). Economically, an investor receiving a price $x_{1}$ subjected to a constant mean $x_{2}$ is subjected to a fair market with non-arbitrage conditions as one is equally subjected to price increase as well as price decrease about the mean.

Figure 5 presents a scenario when both volatilities $\sigma_{1}$ and $\sigma_{2}$ are non-zero. It can be seen that if both volatilities are non-zero then both price processes fluctuate. Like the scenario in Figure 4 there are no arbitrage opportunities as the price $x_{1}$ is as much above $x_{2}$ as it is below.

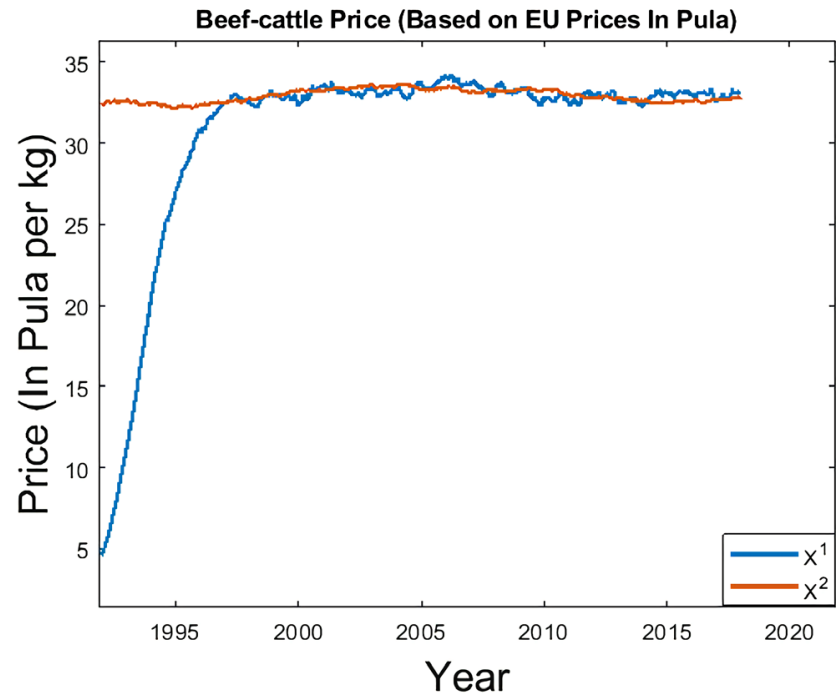

(a)

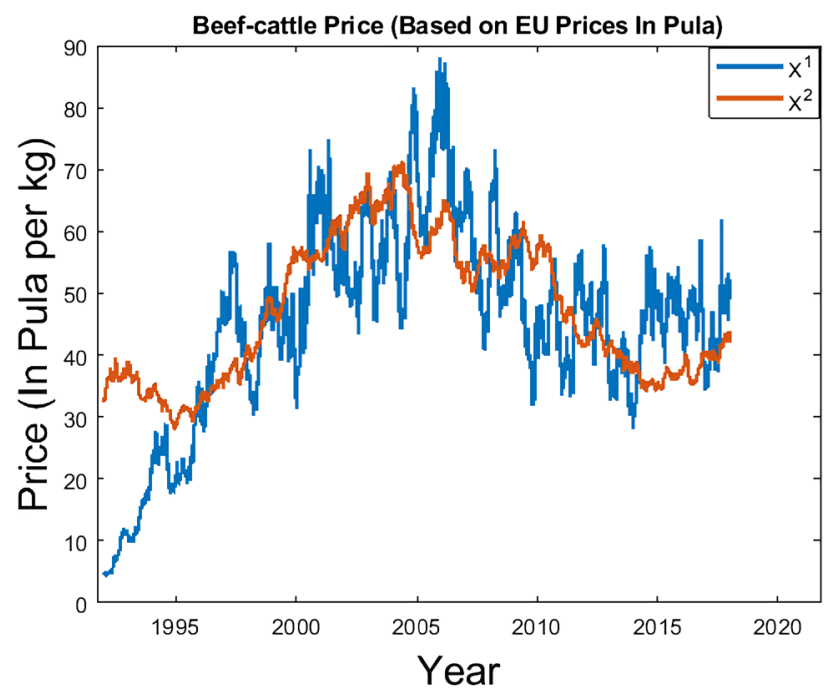

(c)

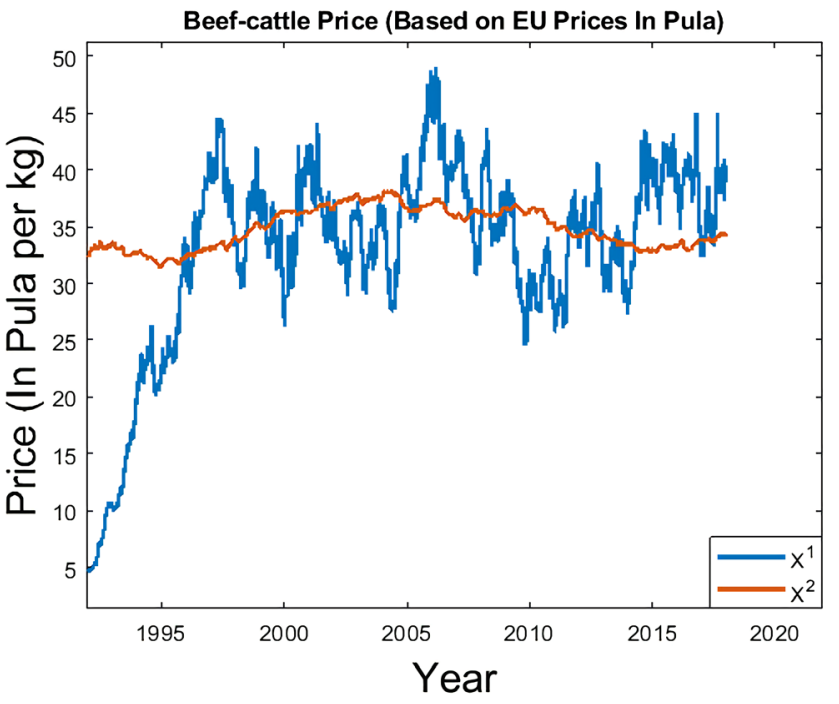

(b)

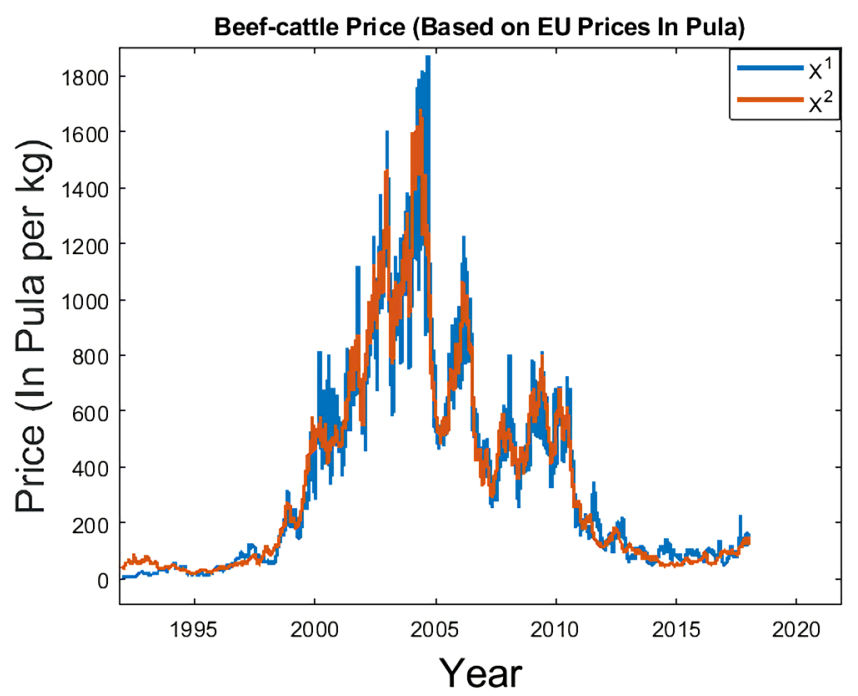

(d)

Figure 5. Botswana beef-cattle prices following Stochastic GMR and mean-reversion level for varying $\sigma_{1}$ and $\sigma_{2}$. (a) $\sigma_{1}=0.019, \sigma_{2}=0.005$

(b) $\sigma_{1}=0.124, \sigma_{2}=0.021$

(c) $\sigma_{1}=0.1, \sigma_{2}=0.4$

(d) $\sigma_{1}=0.5, \sigma_{2}=0.9$. 
However, if both noises ( $\sigma_{1}$ and $\sigma_{2}$ ) are large (Figure 5(d)) even if the difference between the volatilities is large the two prices do not differ significantly. The advantage between the prices, depicted by Figure 5(c) and Figure 5(d) vanishes as the two price processes seem to overlap.

Figure 6 shows the returns $\left(r_{1}\right)$ on the price $x_{1}$ for varying values of $\sigma_{1}$ and $\sigma_{2}$. Figure 6(a) represents a scenario when both $\sigma_{1}$ and $\sigma_{2}$ are zero. The mean price $x_{2}$ remains constant (assumed to be zero in this case) but $r_{1}$ increases initially to a peak but declines to zero and remains zero. In the long run if there is no noise, there is no benefit from selling cattle but more importantly the BMC is subjected to no growth in returns.

Figure $6(\mathrm{~b})$ shows that when there is noise in the $\mathrm{BMC}$ price then the cattle price will fluctuate about the BMC beef price which remains constant. Farmers can now gain or loss as the cattle price is above the beef price as it is below. The most ideal scenarios are given by Figure 6(d) and Figure 6(e) where both the

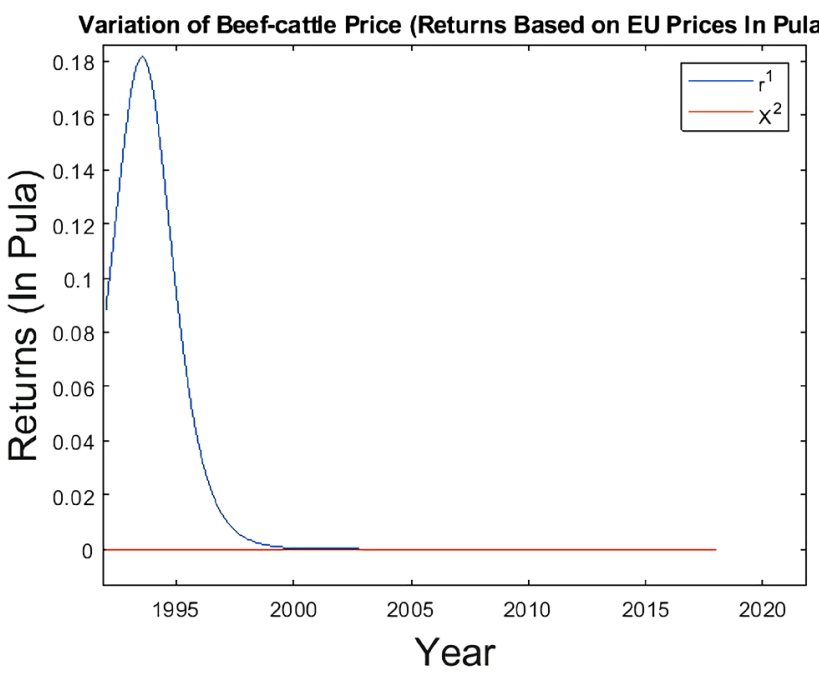

(a)

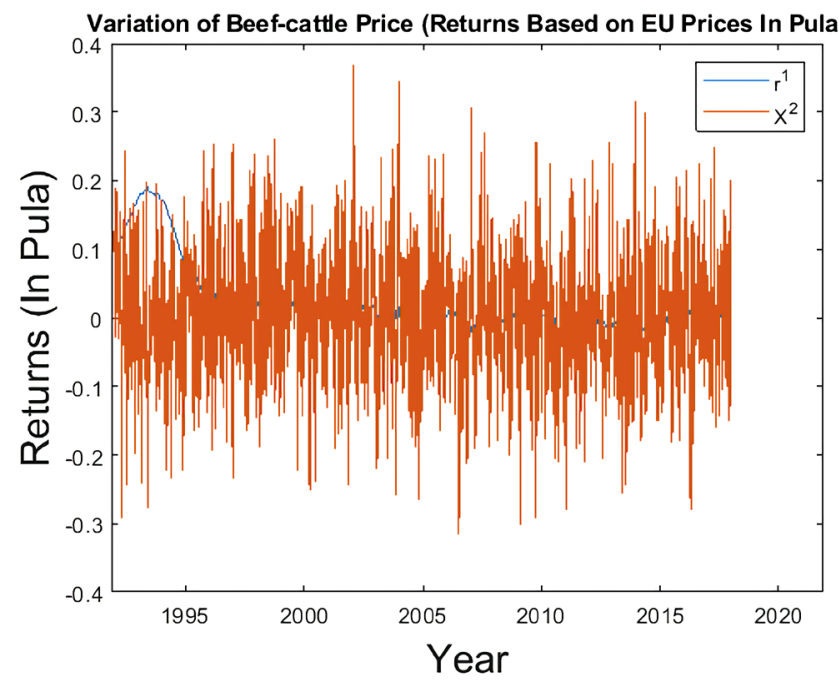

(c)

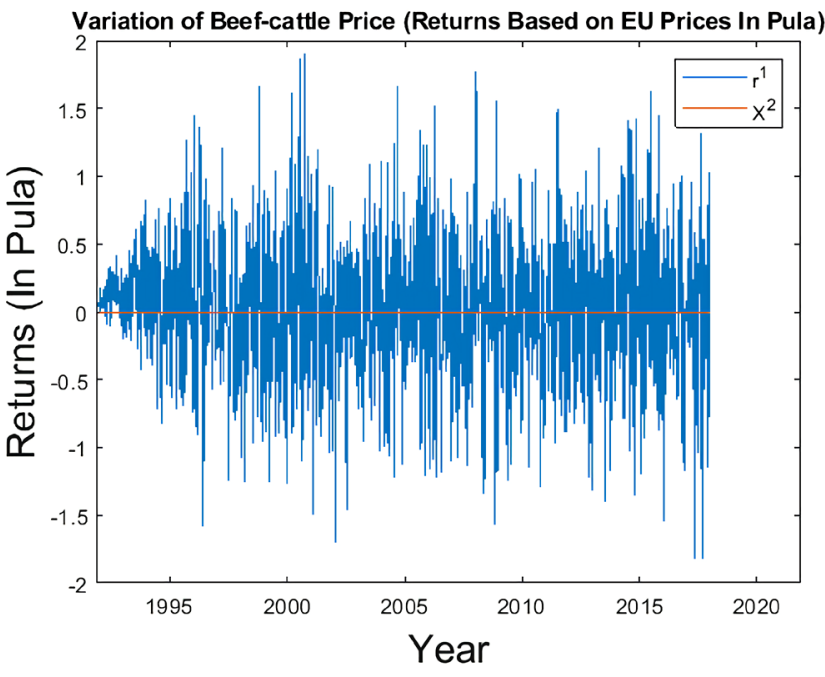

(b)

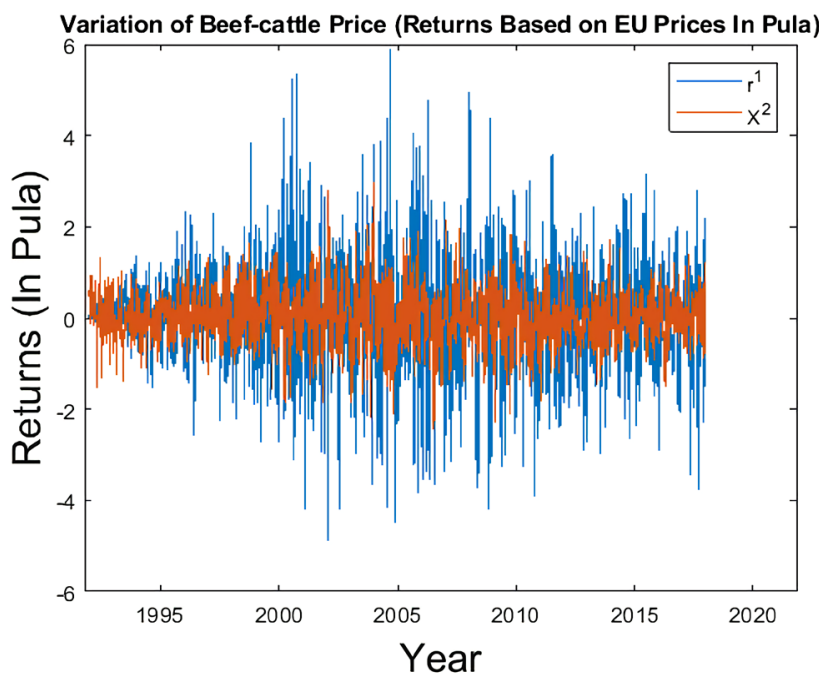

(d) 


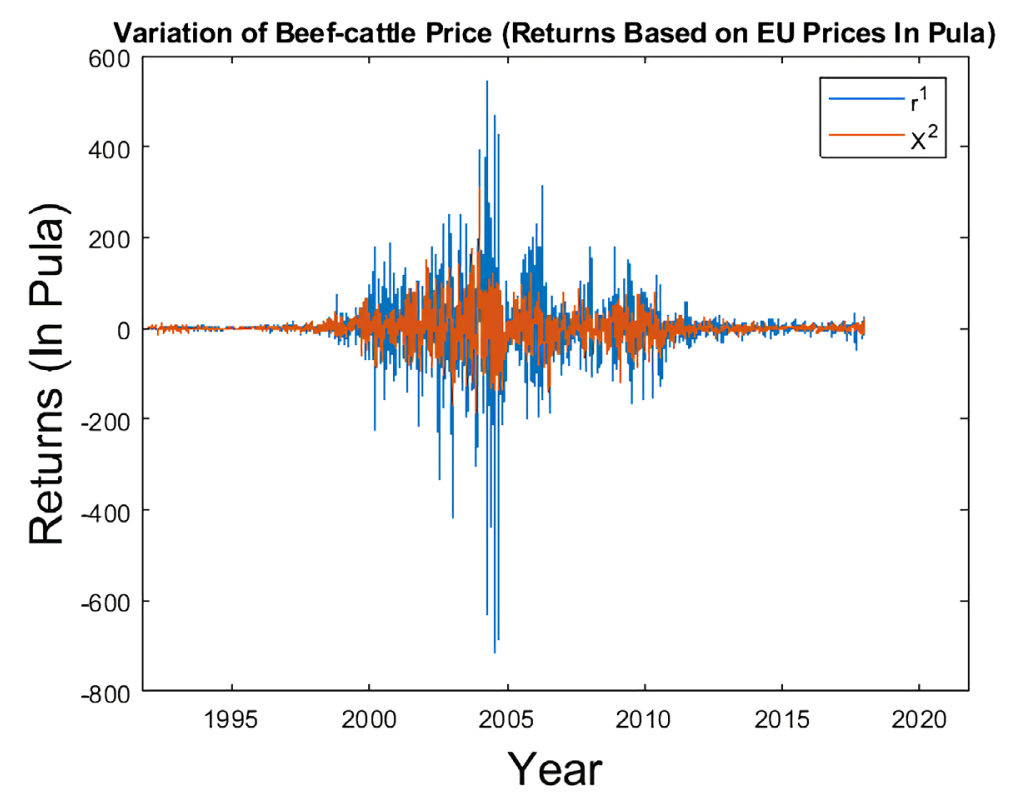

(e)

Figure 6. The variation of beef-cattle price (returns) (a) $\sigma_{1}=0, \sigma_{2}=0$ (b) $\sigma_{1}=0.124, \sigma_{2}=0$ (c) $\sigma_{1}=0, \sigma_{2}=0.021$ (d) $\sigma_{1}=0.2, \sigma_{2}=0.1 \quad$ (e) $\sigma_{1}=0.7, \sigma_{2}=0.5$.

cattle price and the beef price fluctuate and consequently removing any arbitrage opportunities.

\section{Conclusions and Discussion}

We have shown through a bivariate analysis in Section 2.2 that the price the EU offers to the BMC and the price the BMC offers to the cattle farmers are highly correlated with the difference between them explained by a white noise process. This suggests that the middle agent, in this case the BMC, is left with insignificant amounts to support their operations such as maintenance and salaries. Based on this conclusion, we formulated a stochastic model of the Ornstein-Uhlenbeck type with the BMC-EU price as the stochastic mean of the Farmer-BMC price. We have shown that when both volatilities are zero $\left(\sigma_{1}=\sigma_{2}=0\right)$, the Farmer-BMC price increases to the mean price and remains at that level. This situation is of course uneconomical for BMC as they operate as an intermediary agent which is passing on to the farmer everything received from selling beef to the EU. BMC would obviously not manage to maintain their operations as they would have no capital to service their processing plant and pay salaries. BMC has in recent years run into operational problems, with operations subsidized from government handouts. The situation described for $\sigma_{1}=\sigma_{2}=0$ could partly explain some of the difficulties the company is subjected to.

When the volatility for the farmers' price is kept at $\sigma_{1}=0$, but the volatility $\sigma_{2}$ is nonzero, the farmers' price fluctuates about the EU mean price. There is then a quasi but variable stability in the sense that the prices $x_{1}(t)$ and $x_{2}(t)$ remain close. However, when the volatility $\sigma_{2}$ grows large the difference in the 
two prices vanishes. This situation is again not conducive to the BMC. When the EU mean price is kept constant (by taking the volatility equal to zero) but the farmer price varies by increasing the volatility of the farmer price $\sigma_{1}$, there is a big difference between the farmer price and the EU price. We believe that this is the preferred scenario for the farmer. It can be achieved by among other things, increasing and diversifying the number of beef consumers and cattle buyers locally and regionally. The farmers should look for local and regional buyers of their cattle instead of relying on the BMC. The BMC, in turn, should source regional markets for their beef instead of relying on the EU. Sub-Saharan Africa is a large market comprising of over 1 billion consumers. This is the market that BMC should target. We believe that government intervention is one of the reasons, the price that the BMC offers to the farmers is kept artificially high because the government is trying to eradicate poverty by artificially keeping the price of cattle high without due consideration of what price the EU is offering the BMC.

\section{Acknowledgements}

The authors acknowledge with gratitude the support from the Simons Foundation (US) through the Research and Graduate Studies in Mathematics (RGSMA) project at Botswana International University of Science and Technology (BIUST) and the Departments of Mathematics and Statistical Sciences of BIUST.

\section{Conflicts of Interest}

The authors declare no conflicts of interest regarding the publication of this paper.

\section{References}

[1] Stevens, C. and Kennan, J. (2005) Botswana Beef Exports and Trade Policy.

[2] Piot-Lepetit, I. and M’Barek, R. (2011) Methods to Analyse Agricultural Commodity Price Volatility. Springer, Berlin, 1-11. https://doi.org/10.1007/978-1-4419-7634-5 1

[3] Geman, H. (2009) Commodities and Commodity Derivatives: Modeling and Pricing for Agriculturals, Metals and Energy. John Wiley \& Sons, Hoboken.

[4] Dizyee, K., Baker, D. and Rich, K.M. (2017) A Quantitative Value Chain Analysis of Policy Options for the Beef Sector in Botswana. Agricultural Systems, 156, 13-24. https://doi.org/10.1016/j.agsy.2017.05.007

[5] Jefferis, K. (2007) Price Responsiveness of Cattle Supply in Botswana. Policy Briefing Paper. Southern Africa Global Competitiveness Hub, Gaborone. http://www.econsult.co.bw/tempex/PriceResponsivenessofCattleSupplyinBotswana. pdf

[6] Gosalamang, D.S. (2010) Econometric Analysis of Supply Response among Beef Farmers in Botswana. PhD Thesis, University of Limpopo, Mankweng.

[7] Statistics Botswana (2017) Annual Agricultural Survey Report 2017. Statistics Botswana, Gaborone.

[8] Botswana-Meat Exports Quantity. https://knoema.com/atlas/Botswana/topics/Agriculture/Trade-Export-Quantity/Me 
at-exports-quantity

[9] Tothova, M. (2011) Main Challenges of Price Volatility in Agricultural Commodity Markets. In: Methods to Analyse Agri-Cultural Commodity Price Volatility, Springer, Berlin, 13-29. https://doi.org/10.1007/978-1-4419-7634-5 2

[10] Schwartz, E.S. (1997) The Stochastic Behavior of Commodity Prices: Implications for Valuation and Hedging. The Journal of Finance, 52, 923-973. https://doi.org/10.1111/j.1540-6261.1997.tb02721.x

[11] Schwartz, E. and Smith, J.E. (2000) Short-Term Variations and Long-Term Dynamics in Commodity Prices. Management Science, 46, 893-911.

https://doi.org/10.1287/mnsc.46.7.893.12034

[12] Casassus, J. and Collin-Dufresne, P. (2005) Stochastic Convenience Yield Implied from Commodity Futures and Interest Rates. The Journal of Finance, 60, 2283-2331. https://doi.org/10.1111/j.1540-6261.2005.00799.x

[13] Bessembinder, H., Coughenour, J.F., Seguin, P.J. and Smoller, M.M. (1995) Mean Reversion in Equilibrium Asset Prices: Evidence from the Futures Term Structure. The Journal of Finance, 50, 361-375. https://doi.org/10.1111/j.1540-6261.1995.tb05178.x

[14] Pindyck, R.S. (2001) The Dynamics of Commodity Spot and Futures Markets: A Primer. The Energy Journal, 22, 1-30. https://doi.org/10.5547/ISSN0195-6574-EJ-Vol22-No3-1

[15] Routledge, B.R., Seppi, D.J. and Spatt, C.S. (2000) Equilibrium Forward Curves for Commodities. The Journal of Finance, 55, 1297-1338. https://doi.org/10.1111/0022-1082.00248

[16] Dixit, A.K. and Pindyck, R.S. (1994) Vinvestment under uncertaintyv.

[17] Box, G. (2013) Box and Jenkins: Time Series Analysis, Forecasting and Control. In: A Very British Affair, Springer, Berlin, 161-215. https://doi.org/10.1057/9781137291264 6

[18] Box, G. and Jenkins, G. (1970) Time Series Analysis-Forecasting and Control. Holden Day, San Francisco, 553 p.

[19] Ewald, C.-O. and Yang, Z.J. (2007) Geometric Mean Reversion: Formulas for the Equilibrium Density and Analytic Moment Matching.

[20] Asfaw, M.D., Kassa, S.M. and Lungu, E.M. (2019) Stochastic Plant-Herbivore Interaction Model with Allee Effect. Journal of Mathematical Biology, 79, 2183-2209. https://doi.org/10.1007/s00285-019-01425-5

[21] Gard, T.C. (1988) Introduction to Stochastic Differential Equations. Monographs and Text-Books in Pure and Applied Mathematics. Dekker, Inc., New York.

[22] Øksendal, B. (2010) Stochastic Differential Equations: An Introduction with Applications. Universitext. Springer, Berlin.

[23] European Commission (2018) Beef Prices. https://ec.europa.eu/info/food-farming-fisheries/farming/facts-and-figures/markets loverviews/market-observatories/meat/beef-statistics en

[24] Euro Botswana Pula Exchange Rate History (EUR BWP). https://currencies.zone/historic/euro/botswana-pula

[25] Pachamanova, D.A. and Fabozzi, F.J. (2014) Recent Trends in Equity Portfolio Construction Analytics. The Journal of Portfolio Management, 40, 137-151. https://doi.org/10.3905/jpm.2014.40.3.137 
Appendix A1: Farmer-BMC Prices $S_{1}(t)$, BMC-EU Prices $S_{2}(t)$ and Their Respective Residuals

Table A1. Farmer-BMC prices $S_{1}(t)$ and BMC-EU prices $S_{2}(t)$ for the years 1992 to 2018.

\begin{tabular}{|c|c|c|c|c|}
\hline Year & $S_{1}(t)$ & $S_{1}(t)-\bar{S}_{1}$ & $S_{2}(t)$ & $S_{2}(t)-\bar{S}_{2}$ \\
\hline 1992 & 4.56 & -7.85 & 7.06 & -16.29 \\
\hline 1993 & 4.17 & -824 & 7.75 & 15.61 \\
\hline 1994 & 4.55 & -7.86 & 7.85 & -15.51 \\
\hline 1995 & 4.62 & -7.79 & 6.94 & -16.42 \\
\hline 1996 & 4.23 & -8.18 & 11.56 & -11.82 \\
\hline 1997 & 4.17 & -8.24 & 10.95 & -12.41 \\
\hline 1998 & 4.78 & -7.63 & 11.19 & -12.16 \\
\hline 1999 & 4.65 & -7.76 & 12.31 & -11.04 \\
\hline 2000 & 4.53 & -7.88 & 11.25 & -12.1 \\
\hline 2001 & 4.45 & -7.96 & 2.45 & -10.91 \\
\hline 2002 & 4.62 & -7.97 & 14.32 & -9.02 \\
\hline 2003 & 4 & -8.41 & 15.45 & -7.9 \\
\hline 2004 & 4.52 & -7.89 & 16.2 & -7.16 \\
\hline 2005 & 6.71 & -5.7 & 17.19 & -6.17 \\
\hline 2006 & 8.3 & -4.11 & 20.89 & -2.46 \\
\hline 2007 & 12.13 & -0.8 & 24.38 & 1.03 \\
\hline 2008 & 13.51 & 1.1 & 29.34 & 5.98 \\
\hline 2009 & 19.51 & 7.1 & 32.27 & 8.92 \\
\hline 2010 & 24.23 & 11.82 & 30.67 & 7.32 \\
\hline 2011 & 23.64 & 11.23 & 31.31 & 7.96 \\
\hline 2012 & 14.4 & 1.99 & 37.56 & 14.21 \\
\hline 2013 & 15.45 & 3.04 & 41.35 & 17.21 \\
\hline 2014 & 29 & 16.59 & 45.64 & 22.29 \\
\hline 2015 & 12.5 & 0.09 & 41.78 & 18.43 \\
\hline 2016 & 33 & 20.59 & 45.9 & 22.54 \\
\hline 2017 & 32.73 & 20.32 & 42.57 & 19.22 \\
\hline 2018 & 32.2 & 19.79 & 44.45 & 21.1 \\
\hline Mean $\left(\bar{S}=\frac{1}{n} \sum_{i=1}^{n}{ }^{\gamma} S_{i}\right)$ & 12.41 & & & 23.35 \\
\hline
\end{tabular}

The sum of residuals for the two prices are;

1) Farmer-BMC price: $\sum_{i=1}^{n}\left(S_{1, i}-\bar{S}_{1}\right)=0.00333$ and

2) BMC-EU price: $\sum_{i=1}^{n}\left(S_{2, i}-\bar{S}_{2}\right)=0$ 


\section{Appendix A2: New Data Based on the Authors' Assumption} of the Relationship between $S_{1}(t)$ and $S_{2}(t)$

Take the residual of $b$ and find its mean and the results are presented in Table A2.

Table A2. Farmer-BMC prices $S_{1}(t)$ and BMC-EU prices $S_{2}(t)$ for the years 1992 to 2018.

\begin{tabular}{|c|c|c|c|c|}
\hline Year & $S_{1}(t)$ & $S_{2}(t)$ & $b=\left(S_{2}(t)-S_{1}\right)$ & $a$ \\
\hline 1992 & 4.56 & 7.062 & 2.5 & -8.44074 \\
\hline 1993 & 4.17 & 7.75 & 3.58 & -7.36074 \\
\hline 1994 & 4.55 & 7.85 & 3.3 & -7.64074 \\
\hline 1995 & 4.62 & 6.94 & 2.32 & -8.62074 \\
\hline 1996 & 4.23 & 11.56 & 7.31 & -3.63074 \\
\hline 1997 & 4.17 & 10.95 & 6.78 & -4.16074 \\
\hline 1998 & 4.78 & 11.19 & 6.41 & -4.53074 \\
\hline 1999 & 4.65 & 12.31 & 7.66 & -3.28074 \\
\hline 2000 & 4.53 & 11.25 & 6.72 & -4.22074 \\
\hline 2001 & 4.45 & 2.45 & 8 & -2.94074 \\
\hline 2002 & 4.62 & 14.32 & 9.7 & -1.24074 \\
\hline 2003 & 4 & 15.45 & 11.45 & 0.50926 \\
\hline 2004 & 4.52 & 16.2 & 11.68 & 0.73926 \\
\hline 2005 & 6.71 & 17.19 & 10.48 & -0.46074 \\
\hline 2006 & 8.3 & 20.89 & 12.59 & 1.64926 \\
\hline 2007 & 12.13 & 24.38 & 12.25 & 1.30926 \\
\hline 2008 & 13.51 & 29.34 & 15.83 & 4.88926 \\
\hline 2009 & 19.51 & 32.27 & 12.76 & 1.81926 \\
\hline 2010 & 24.23 & 30.67 & 6.44 & -4.50074 \\
\hline 2011 & 23.64 & 31.31 & 7.67 & -3.27074 \\
\hline 2012 & 14.4 & 37.56 & 23.16 & 12.21926 \\
\hline 2013 & 15.45 & 41.35 & 25.9 & 14.95926 \\
\hline 2014 & 29 & 45.64 & 16.64 & 5.69926 \\
\hline 2015 & 12.5 & 41.78 & 29.28 & 18.33926 \\
\hline 2016 & 33 & 45.9 & 12.9 & 1.95926 \\
\hline 2017 & 32.73 & 42.57 & 9.84 & -1.10074 \\
\hline 2018 & 32.2 & 44.45 & 12.25 & 1.30926 \\
\hline Mean $\left(\bar{S}=\frac{1}{n} \sum_{i=1}^{n} \backslash S_{i}\right)$ & 12.4 & 10.94074 & 23.35 & \\
\hline
\end{tabular}

Where $b=S_{2, i}-S_{1, i}$. Note that the sum of the residuals $a_{i}$ is zero. 


\section{Appendix A3. Numerical Approximation and Model Calibration}

In line with least squares approximation, the system (21)-(22) can be be written as follows,

$$
\begin{gathered}
x_{1, t+1}=x_{1, t}+\kappa\left(x_{2}-x_{1, t}\right) x_{1, t}+\sigma_{1} x_{1, t} \epsilon_{1, t} \\
x_{2, t+1}=\sigma_{2} x_{2, t} \epsilon_{2, t} .
\end{gathered}
$$

where $\epsilon_{1, t}$ and $\epsilon_{2, t}$ are standard normal variables. The technique for least squares is tied in estimating parameters by minimizing the squared errors of historical data, from one perspective, and their expected values on the other. The approach we used takes the form of a regression problem, where the variation in one variable, called the dependent variable $Y$, can be partly explained by the variation in the other variables, called independent variables say $X$. To estimate the parameters $\kappa, X_{2}, \sigma_{1}$ and $\sigma_{2}$ we used weekly spot prices of beef-cattle from the EU markets for years 2003 to 2018. The choice of 2003 as the initial observation was mainly conditioned by the availability of data. We got weekly beef prices from an official website of the EU [23]. The prices were converted into Botswana Pula (BWP) using the exchange rates we obtained from [24]. Assuming constant parameters during the time period of estimation and rewrite the system (21)-(22) as,

$$
\begin{gathered}
\frac{x_{1, t+1} x_{1, t}}{x_{1, t}}=\kappa x_{2}-\kappa x_{1, t}+\sigma_{1} \epsilon_{1, t} \\
x_{2, t_{1}}=x_{2, t} \sigma_{2} \epsilon_{2, t}
\end{gathered}
$$

Both Equations (52) and (53) bears the characteristics of a linear regression model, with the gain and loss given by $\frac{x_{1, t+1} x_{1, t}}{x_{1, t}}$ and $x_{2, t+1}$ as dependent variables, $x_{1, t}$ and $x_{2, t}$ as explanatory variables. Following the work by [25], the estimates of $\kappa$ and volatility $(\sigma s)$ are obtained as the negative of the coefficient in front of $x_{1, t}$ and the standard error of the regression respectively (see Table A3 for results).

Table A3. Parameter estimates for beef-cattle prices based on the EU.

\begin{tabular}{cccccc}
\hline Parameter & $\kappa$ & $m\left(x_{2}\right)$ & $x_{1}(0)$ & $\sigma_{1}$ & $\sigma_{2}$ \\
\hline EU Beef-cattle Price & 0.036 & 32.35 & 4.56 & 0.124 & 0.0210 \\
\hline
\end{tabular}

Source: Authors' estimates based on the EU market [23].

As a good start to the numerical methods for the system (21)-(22) we consider the Euler-Mayurama method to simulate the stochastic differential equations. Given the system (21)-(22), the Euler-Maruyama method generates a discrete sequence $x_{t}=\left\{x_{t}^{j}\right\}_{j \in\{1, \cdots, d\}}$, which approximates the system on the interval $[0, T]$. From the system (21)-(22) we have, 


$$
\begin{aligned}
x_{1, t_{i+1}}^{j} & =x_{1, t_{i}}^{j}+\kappa\left(x_{2, t_{i}}^{j}-x_{1, t_{i}}\right) x_{1, t_{i}}^{j} \Delta_{t, i}+x_{1, t_{i}}^{j} \sigma_{1}\left(W_{t_{i}+1}^{1}-W_{t_{i}}^{2}\right) \\
& =x_{1, t_{i}}^{j}+\kappa\left(x_{2, t_{i}}^{j}-x_{1, t_{i}}\right) x_{1, t_{i}}^{j} \Delta_{t, i}+\sigma_{1} x_{1, t_{i}}^{j} \sqrt{t_{i+1}-t_{1} \epsilon^{j}} \\
x_{2, t_{i+1}}^{j} & =x_{2, t_{i}}^{j}+x_{2, t_{i}}^{j} \sigma_{2}\left(W_{t_{i}+1}^{2}-W_{t_{i}}^{2}\right)=\sigma_{2} x_{2, t_{i}}^{j} \sqrt{t_{i+1}-t_{1} \epsilon^{j}} .
\end{aligned}
$$

where $X_{t, 0}=X_{0}, X_{t, 0}=\left(x_{1, t_{0}}, x_{2, t_{0}}\right), \Delta_{t, i}=t_{i+1}-t_{i}$, for $i=0, \cdots, N$ and $\epsilon$ is a Gaussian process with mean 0 and co-variance $\mathbb{1}$ (identity matrix). It is an iterative technique as the solution of the stochastic differential equation is changed at every step.

\section{Appendix A4. Weekly Beef Prices Based on the EU Market}

In Figure 7 are the weekly beef average market prices for the European Union as from January 2003 to December 2018. The figure depicts some changing levels and trends are neither linear nor quadratic. In order to calculate the initial value for $x_{2}$ (i.e. the mean), we sum all the observed prices starting from 2003 to 2018 and divide it by the number of observations $n$. The following formula was used,

$$
x_{2}(0)=\bar{x}_{2}=\frac{1}{n} \sum_{i=1}^{n} x_{2, i}{ }^{\dagger}
$$

The data used in this study consisted of $n=835$ weekly observations and we obtained $x_{2}(0)=32.35$. Agriculture commodities are transnational products of which the Botswana Beef-cattle is not exceptional and are traded usually having historical data series. In particular, the future volatility rate $\sigma$ from the system (21)-(22) is estimated from the historic volatility of beef cattle prices, based on the standard deviation of the time series, given by equation:

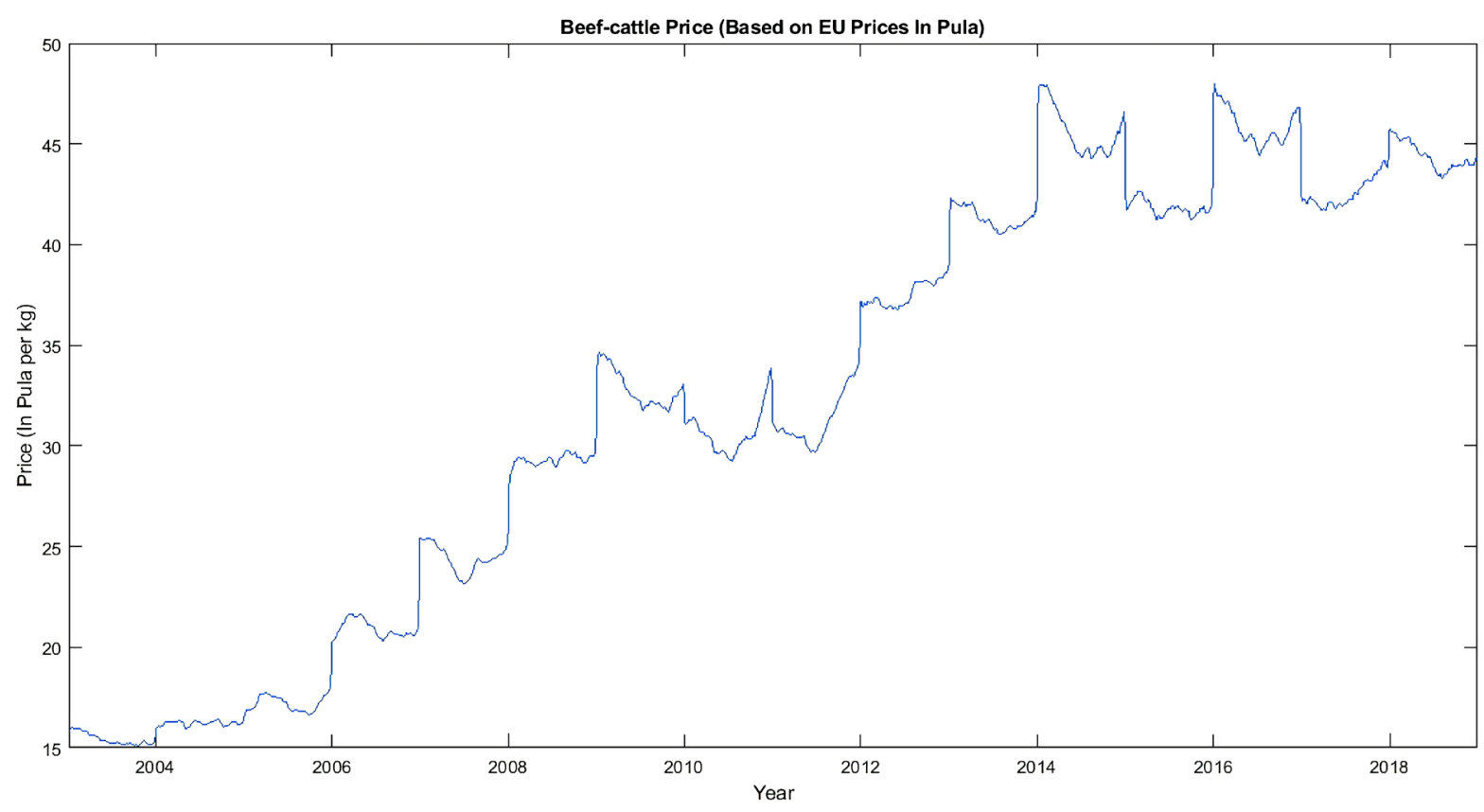

Figure 7. European union beef average market price. 


$$
\sigma=\sqrt{\frac{1}{n-1} \sum \ngtr(S(t)-\bar{S})^{2}}
$$

The drift part of Equation (21) describes the time evolution of beef-cattle prices the continually yield at a rate $\kappa\left(x_{2}-x_{1}\right) x_{1}$, which is represented as a combination of mean-reversion force $\kappa$, the average of the EU historical beef prices (assumed to be stochastic) and the cattle prices (Farmer-BMC).

In Table $\mathrm{A} 4$ are the notations that were used in this paper.

Table A4. Notations and symbols.

\begin{tabular}{|c|c|}
\hline Notation & Description \\
\hline BWP & Botswana Pula \\
\hline$S(t)$ & Beef-cattle price at time $t$ \\
\hline $\bar{S}$ & Average beef-cattle price \\
\hline \multirow[t]{2}{*}{$S_{1}(t), S_{2}(t)$} & Farmer-BMC price and BMC-EU respectively price at time \\
\hline & ( for simplicity we have denoted by $x_{1}$ and $x_{2}$ respectively) \\
\hline$a_{1}, a_{2}$ & Respective residuals for $S_{1}$ and $S_{2}$ \\
\hline$r$ & The Pearson's correlation coefficient \\
\hline$r(t)$ & Rate of return \\
\hline$r_{1}, r_{2}$ & Returns for $x_{1}$ and $x_{2}$ respectively \\
\hline$x^{\prime}$ & Prime symbol (for derivative) \\
\hline $\int^{\Uparrow}$ & Integral sign \\
\hline $\mathrm{d}()$. & Differential sign \\
\hline$\sigma_{1}, \sigma_{2}$ & Rate of volatilities for Farmer-BMC price and BMC-EU respectively price \\
\hline$\omega(B)$ & Transfer function \\
\hline$\nabla_{S_{1, t}^{d}}^{d}, \nabla_{S_{2, t}^{d}}^{d}$ & Incremental changes for Farmer-BMC prices and BMC-EU prices respectively \\
\hline $\mathbb{E}[\cdot]$ & Expectation operator \\
\hline$T \wedge \tau_{\epsilon}$ & Smaller between $T$ and $\tau_{\epsilon}$, where $\epsilon$ is an arbitrary small number \\
\hline$\beta_{t}=\phi_{p}(B) S_{1, t}$ & Autoregressive process $\operatorname{AR}(p)$ of order $p$ \\
\hline & where, $\phi(B)=1-\phi_{1} B-\cdots-\phi_{p} B^{p}$ \\
\hline$\alpha_{t}=\theta_{q}(B) S_{2, t}$ & Moving average $\operatorname{MA}(q)$ of order $q$ \\
\hline & where, $\theta(B)=1-\theta_{1} B-\cdots-\theta_{q} B^{q}$ \\
\hline$\Delta_{t, i}=t_{i}-t_{i-1}$ & Time interval \\
\hline $\mathbb{P}()$. & Probability of (.) \\
\hline
\end{tabular}

